\title{
Peningkatan Minat Baca dengan Program Generasi Masyarakat Gemar Membaca di RPTRA Cililitan Jakarta Timur
}

\author{
Putri Winda Lestari*1, Hanifah Nur Izzah², Mega Kartika Yudyaningtyas ${ }^{3}$ \\ 1,2,3 Program Studi K3, Fakultas Kesehatan Masyarakat, Universitas Binawan \\ *e-mail: winda@binawan.ac.id ${ }^{1}$
}

\begin{abstract}
Reading has many benefits, one of which is opening the world. PISA research shows a low level of Indonesian literacy compared to countries in the world. Needs to be done to foster interest in reading from an early age and apply it to the community. Based on the initial survey, The Cililitan RPTRA has good facilities, such as the availability of a library room. The number of visitors to the library room is small. We can see that there is a low interest in reading at The Cililitan RPTRA visitors. This activity purpose to achieve a high interest in reading in The Cililitan RPTRA, East Jakarta. The method of activity is community development, encapsulated under the name of The Generation of Reading Fondness Program. Based on interviews with The Cililitan RPTRA visitors this program can increase reading interest. Socialization about the importance of reading needs to be done continuously. Other activities that can upgrade interest in reading such as storytelling and educational games. Procurement of books can be a solution to increase reading choices for visitors to The Cililitan RPTRA.
\end{abstract}

Keywords: Interest in reading, society, RPTRA.

\begin{abstract}
Abstrak
Membaca memiliki banyak manfaat, salah satunya adalah membuka jendela dunia. Penelitian PISA menunjukkan rendahnya tingkat literasi Indonesia dibanding negara-negara di dunia. Perlu dilakukan upaya untuk menumbuhkan minat baca sejak dini dan menerapakannya pada masyarakat. Berdasarkan survey awal, RPTRA Cililitan memiliki fasilitas lengkap, seperti tersedianya ruang perpustakaan. Namun, jumlah pengunjung di ruang perpustakaan cenderung sedikit. Dapat kita lihat bahwa masih kurangnya minat baca pengunjung RPTRA Cililitan. Kegiatan ini bertujuan untuk meningkatkan minat baca melalui program Generasi Masyarakat Gemar Membaca di RPTRA Cililitan Jakarta Timur. Metode kegiatan adalah community development, dikemas dengan nama Program Generasi Gemar Membaca. Berdasarkan wawancara dengan pengunjung RPTRA Cililitan, Program Generasi Gemar Membaca mampu meningkatkan ketertarikan mereka terhadap buku dan meningkatkan minat baca. Sosialisasi tentang pentingnya membaca perlu dilakukan secara terus-menerus. Kegiatan lain yang dapat menarik minat baca antara lain story telling dan permainan edukasi. Pengadaan buku dapat menjadi solusi untuk meningkatkan opsi bacaan bagi pengunjung RPTRA Cililitan.
\end{abstract}

Kata kunci: Minat baca, Masyarakat, RPTRA

\section{PENDAHULUAN}

Pintu gerbang penguasaan ilmu pengetahuan adalah dengan banyak membaca. Sebab dengan membaca dapat membuka jendela dunia. Sehingga cara berpikir masyarakat kita akan maju dan keluar dari zona kemiskinan menuju kehidupan yang sejahtera (Sularso, 2020). Membaca memiliki banyak manfaat diantaranya yaitu dapat menstimulasi otak, mengurangi stress, menambah wawasan dan pengetahuan, menambah kosa kata, meningkatkan kualitas memori, melatih keterampilan berpikir dan menganalisis, meningkatkan fokus dan konsentrasi, meningkatkan kemampuan menulis, memperluas pemikiran seseorang, meningkatkan hubungan sosial, serta membantu terhubung dengan dunia luar (Patiung, 2016).

Penelitian PISA menunjukkan rendahnya tingkat literasi Indonesia dibanding negaranegara di dunia. Indonesia masih belum beranjak dari papan bawah. Berturut-turut, nilai untuk membaca, matematika, dan sains dari hasil tes pada tahun 2018 adalah 371, 379, dan 396. Nilai ini mengalami penurunan dibanding tes yang dilakukan tahun 2015, di mana berturut-turut membaca, matematika, dan sains kita meraih skor 397, 386, 403. Dari semua skor itu, membaca memiliki penurunan skor terendah. Indonesia berada di peringkat 72 dari 77 negara, dengan kata lain enam peringkat terbawah (OECD, 2015; OECD, 2019). 
Rendahnya minat baca masyarakat kita sangat mempengaruhi kualitas bangsa Indonesia. Rendahnya minat baca menyebabkan kita tidak dapat mengikuti perkembangan ilmu pengetahuan dan informasi di dunia, di mana pada akhirnya akan berdampak pada ketertinggalan bangsa Indonesia. Majunya suatu Negara dipengaruhi oleh kualitas sumber daya manusia yang unggul. Budaya membaca di Negara maju telah mendarah daging dan sudah menjadi kebutuhan mutlak dalam kehidupan sehari harinya. Oleh karena itu kita perlu meniru upaya yang dilakukan Negara maju yaitu dengan cara menumbuhkan minat baca sejak dini dan menerapakannya pada masyarakat, terutama pada tunas-tunas bangsa yang kelak akan mewarisi negeri ini (Sularso, 2020).

RPTRA atau Ruang Publik Terpadu Ramah Anak adalah konsep ruang publik berupa ruang terbuka hijau atau taman yang dilengkapi dengan berbagai permainan menarik, pengawasan CCTV, dan ruangan-ruangan yang melayani kepentingan komunitas yang ada di sekitar RPTRA tersebut seperti ruang perpustakaan, PKK Mart, ruang laktasi, dan lainnya. RPTRA Cililitan adalah ruang publik terpadu ramah anak yang terletak di Jalan Buluh, Kramatjati, Jakarta Timur, memiliki luas lahan $3800 \mathrm{~m}^{2}$.

Berdasarkan survey awal yang dilakukan, RPTRA Cililitan memiliki fasilitas yang lengkap, baik dan terawat. Selain ruang terbuka hijah dan fasilitas lainnya, tersedia pula ruang perpustakaan. Namun, sebagian besar pengunjung lebih memilih ruang terbuka hijau atau taman dibandingkan ruang perpustakaan. Jumlah pengunjung di ruang perpustakaan cenderung sedikit. Dapat kita lihat bahwa masih kurangnya minat baca pengunjung RPTRA Cililitan. Padahal, sebagaimana kita ketahui bahwa membaca memiliki banyak manfaat. Membaca merupakan sarana penyerapan pengetahuan, pemahaman, kemampuan analisis, sintesis, dan kemampuan evaluasi. Berdasarkan permasalahan tersebut, tim pengabdian masyarakat tertarik untuk melakukan kegiatan pengabdian masyarakat dengan tujuan agar dapat meningkatkan minat baca melalui program Generasi Masyarakat Gemar Membaca di RPTRA Cililitan Jakarta Timur.

\section{METODE}

Kegiatan pengabdian masyarakat ini dilakukan di RPTRA Cililitan yang berada di Jalan Buluh, Cililitan Kec. Kramatjati, Kota Jakarta Timur pada bulan November 2019 dengan jumlah peserta kegiatan pengabdian masyarakat yang merupakan pengunjung RPTRA sebanyak 10 anak usia sekolah dasar. Metode yang dilakukan adalah community development yang dikemas dengan nama Program Generasi Gemar Membaca.

Program Generasi Gemar Membaca adalah program yang digagas oleh tim pengabdian masyarakat untuk meningkatkan minat baca masyarakat. Program ini terdiri dari beberapa kegiatan, mulai dari pemaparan sosialisasi pentingnya membaca, story telling dan permainan yang dapat meningkatkan minat baca seperti menggambar, bermain tebak kata atau kuis tentang pengetahuan umum serta penyediaan buku bacaan. Peningkatan minat baca diukur secara kualitatif dengan melakukan wawancara mendalam dengan peserta kegiatan pengabdian masyarakat. Tingkat ketercapaian dilihat dari sisi perubahan sikap setelah dilakukan Program Generasi Gemar Membaca.

Langkah-langkah yang ditempuh dalam kegiatan pengabdian masyarakat ini mencakup beberapa tahap yaitu:

a. Tahap persiapan yaitu melakukan koordinasi internal, membuat proposal pengabdian masyarakat, pembagian job desk, membuat instrument yang dibutuhkan (materi edukasi, peralatan menggambar dan daftar presensi), serta melakukan peizinan pada Kepala RPTRA Cililitan.

b. Tahap pelaksanaan yaitu pelaksanaan Program Generasi Gemar Membaca yang terdiri dari terdiri dari beberapa kegiatan, mulai dari sosialisasi tentang pentingnya membaca, story 
telling dan permainan yang dapat meningkatkan minat baca seperti menggambar, bermain tebak kata atau kuis tentang pengetahuan umum serta penyediaan buku bacaan.

\section{HASIL DAN PEMBAHASAN}

\section{a. Sosialisasi tentang Pentingnya Membaca}

Kegiatan pengabdian masyarakat ini, diawali dengan memperkenalkan tim dan tujuan kegiatan pengabdian masyarakat. Kemudian dilanjutkan dengan melakukan diskusi dengan peserta kegiatan pengabdian masyarakat tentang frekuensi membaca buku, buku bacaan yang paling diminati dan kurang diminati, serta bagaimana kebiasaan membaca yang ada di keluarganya masing-masing. Dari diskusi tersebut, diketahui bahwa mereka jarang membaca buku selain buku pelajaran. Sebagian besar peserta kegiatan pengabdian masyarakat mengasosiasikan kegiatan membaca adalah kegiatan yang membosankan. Hal ini dikarenakan apa yang mereka baca bukanlah buku yang mereka minati. Ketika ditanya buku apa yang diminati dan kurang diminati, mereka cenderung bingung karena mereka belum banyak menjelajahi berbagai jenis buku. Mereka hanya menjawab lebih suka membaca komik atau buku bergambar. Kebiasaan membaca buku juga tidak dihidupkan di keluarganya masing-masing kecuali berkaitan dengan tugas sekolah.

Setelah dilakukan diskusi dengan peserta kegiatan pengabdian masyarakat, dilakukan sosialisasi tentang tentang pentingnya membaca baik bagi diri sendiri hingga manfaat membaca dalam jangka panjang bagi Indonesia. Membaca memiliki banyak manfaat yaitu untuk menambah dan memperkaya wawasan berpikir dan memperluas ilmu pengetahuan (Artana, 2015). Membaca juga dapat menstimulasi otak, mengurangi stress, menambah wawasan dan pengetahuan, menambah kosa kata, meningkatkan kualitas memori, melatih keterampilan berpikir dan menganalisis, meningkatkan fokus dan konsentrasi, meningkatkan kemampuan menulis, memperluas pemikiran seseorang, meningkatkan hubungan sosial, serta membantu terhubung dengan dunia luar (Patiung, 2016).

\section{b. Story Telling}

Kegiatan berikutnya setelah sosialisasi adalah story telling. Peserta kegiatan dipersilahkan memilih buku yang ada di ruang perpustakaan RPTRA Cililitan atau buku yang dibawa tim pengabdian. Kemudian tim pengabdian membacakan buku yang telah dipilih. Setelah dilakukan story telling, peserta diajak untuk menceritakan kembali isi buku yang dibaca, nilai moral apa yang mereka dapatkan, serta kesan yang mereka terima. Peserta pengabdian masyarakat mengatakan bahwa kegiatan story telling sangat menarik, karena merupakan sesuatu yang baru bagi mereka. Selama ini membaca hanya dilakukan di sekolah terkait pelajaran atau di rumah jika ada tugas sekolah sehingga dirasa membosankan.

Story telling tidak hanya sekedar aktivitas penceritaan kisah nyata atau fiktif, tetapi lebih ditekankan pada manfaatnya yaitu mengembangkan imajinasi anak, meningkatkan ketrampilan berbahasa, meningkatkan minat baca, membangun kecerdasan emosional, membentuk sifat empati, membantu meningkatkan IQ anak, mengembangkan ketrampilan anak dalam mendengar cerita, serta menanamkan cinta kepada buku (Haryadi \& Ulumuddin, 2018; Dessy Wardiah, 2017).

\section{c. Permainan Edukasi}

Beberapa permainan edukasi yang dilakukan pada kegiatan pengabdian masyarakat ini adalah menggambar, bermain tebak kata dan kuis tentang pengetahuan 
umum. Sebagaimana kita ketahui menggambar memiliki banyak manfaat seperti meningkatkan kreativitas, meningkatkan memori, mengembangkan kemampuan berkomunikasi, meningkatkan kemampuan memecahkan masalah, serta dapat menghilangkan stress (Tirtayati et al., 2014; Widodo \& Harini, 2016).

Permainan tebak kata dan kuis tentang pengetahuan umum juga memiliki banyak manfaat seperti dapat meningkatkan pengetahuan, meningkatkan minat dan hasil belajar (Handayani \& Agustini, 2016). Peserta kegiatan pengabdian masyarakat terlihat antusias dan senang dengan kegiatan permainan edukasi ini.

\section{d. Penyediaan Buku Bacaan}

Untuk menarik minat baca, maka diperlukan sumber bacaan yang bagus dan variatif agar mampu memberikan banyak opsi bacaan bagi pengunjung serta dapat mengakomodasi kebutuhan dari pembaca yang berasal dari berbagai tingkat pendidikan dan usia (Basalamah \& Mohammad Rizal, 2020).

Untuk mewujudkan hal tersebut, maka dilakukan pengadaan buku diupayakan dengan beberapa cara yaitu buku diadakan dengan dana dari tim pengabdian dan hasil sumbangan dari masyarakat. Buku yang sudah disumbangkan berupa buku pelajaran, buku cerita, novel, serta buku kesehatan popular. Harapannya dengan adanya berbagai jenis bacaan, dapat meningkatkan minat baca pengunjung RPTRA Cililitan.

Berdasarkan hasil wawancara mendalam dengan peserta kegiatan pengabdian masyarakat, diketahui bahwa kegiatan sosialisasi pentingnya membaca, strory telling dan permainan edukatif yang dikemas dalam Program Generasi Gemar Membaca mampu meningkatkan minat baca dan kecintaan pada buku. Hal ini dikarenakan mereka memiliki pandangan yang baru tentang buku dan membaca. Membaca bukan lagi hal yang membosankan karena mereka dapat memilih buku bacaan yang mereka minati, tidak ada paksaan atau target yang diberikan. Adanya berbagai pilihan buku yang tersedia di ruang perpustakaan RPTRA Cillitan juga memberikan banyak pilihan bacaan. Kesan yang mereka dapatkan selama kegiatan pengabdian masyarakat ini adalah bahwa membaca dengan metode story telling sangat menarik apalagi dengan adanya story teller yang ekspresif. Kegiatan yang tidak kalah menarik adalah permainan edukasi yang secara tidak langsung dapat meningkatkan pengetahuan dan meningkatkan keaktifan peserta dalam berpendapat dan menjawab pertanyaan. Pengurus RPTRA Cililitan juga merasa senang dengan adanya program dan kunjungan dari rim pengabdian masyarakat.

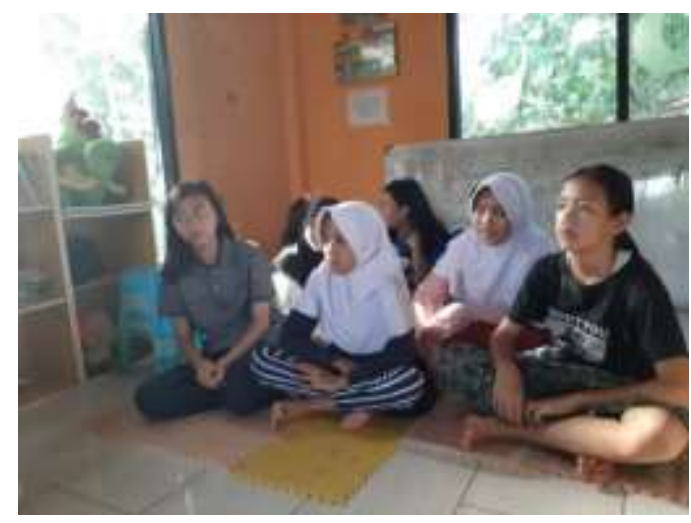

Gambar 1. Kegiatan story telling

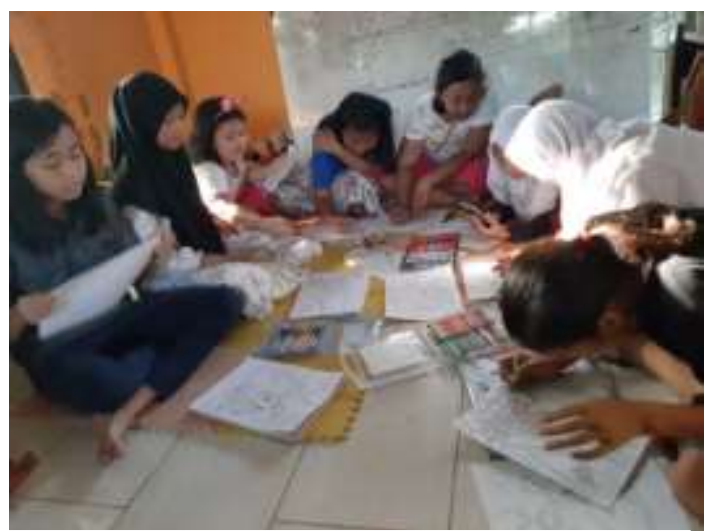

Gambar 2. Kegiatan menggambar 


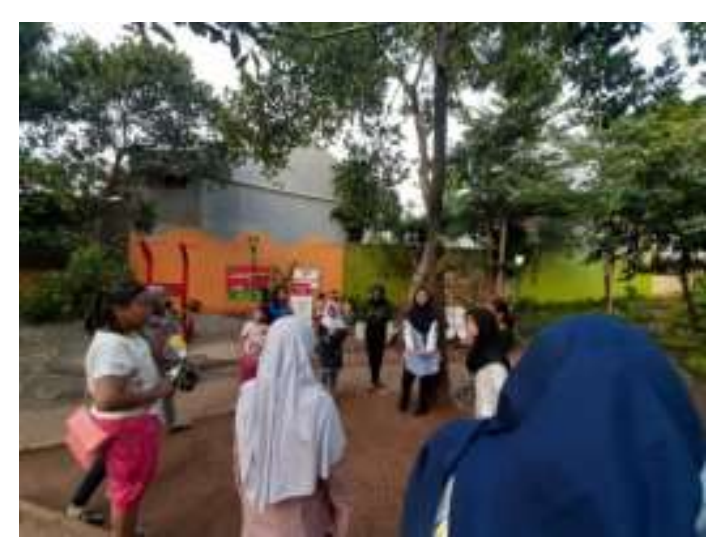

Gambar 3. Permainan edukasi

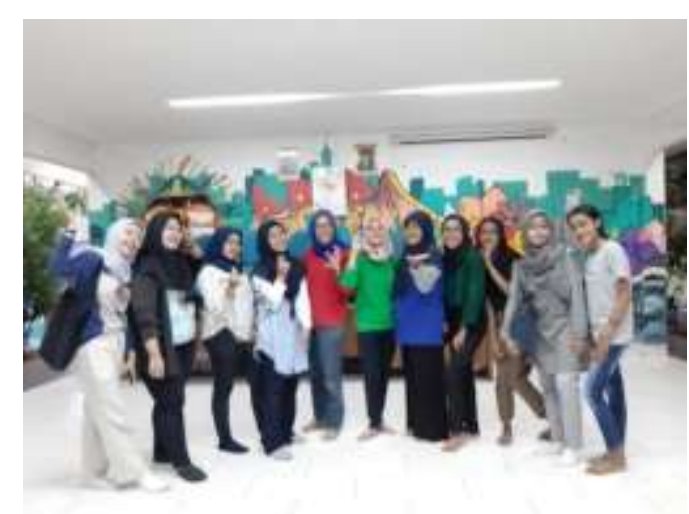

Gambar 4. Tim pengabdi dan pengurus RPTRA

\section{KESIMPULAN}

Kesimpulan harus mengindikasi secara jelas hasil-hasil yang diperoleh, kelebihan dan kekurangannya, serta kemungkinan pengembangan selanjutnya.

Kesimpulan dapat berupa paragraf, namun sebaiknya berbentuk point-point dengan menggunakan numbering atau bullet.

Berdasarkan hasil kegiatan pengabdian masyarakat "Peningkatan Minat Baca dengan Program Generasi Masyarakat Gemar Membaca di RPTRA Cililitan Jakarta Timur" maka dapat disimpulkan:

- Sosialisasi tentang pentingnya membaca perlu dilakukan sehingga dapat meningkatkan kesadaran pengunjung RPTRA Cililitan agar mulai memanfaatkan fasilitas ruang perpustakaan dan buku yang tersedia dengan baik.

- Perlu dilakukan kegiatan lain yang menarik seperti story telling yang secara tidak langsung dapat menarik minat baca dan menimbulkan kecintaan dengan buku.

- Permainan edukasi seperti menggambar, tebak kata dan kuis pengetahuan merupakan alternatif kegiatan yang menyenangkan bagi pengunjung RPTRA Cililitan.

- Pengadaan buku dapat menjadi solusi untuk meningkatkan opsi bacaan bagi pengunjung RPTRA Cililitan.

\section{UCAPAN TERIMA KASIH}

Dalam kegiatan pengabdian masyarakat ini, kami memperoleh banyak bantuan dari berbagai pihak. Terima kasih kepada LPPM Universitas Binawan atas dukungan dalam kegiatan ini, kepada Kepala RPTRA Cililitan yang telah memberikan izin, serta kepada peserta kegiatan pengabdian masyarakat.

\section{DAFTAR PUSTAKA}

Artana, I. K. (2015). Perpustakaan, Masyarakat, dan Pembudayaan Gemar Membaca. Acarya Pustaka, 1(1).

Basalamah, M. R., \& Mohammad Rizal. (2020). Penyediaan Rumah Baca Masyarakat Sebagai Solusi Cerdas Mengawali Budaya Membaca. Dinamisia : Jurnal Pengabdian Kepada Masyarakat, 4(1). https://doi.org/10.31849/dinamisia.v4i1.3756

Dessy Wardiah. (2017). Peran Storytelling Dalam Meningkatkan Kemampuan Menulis, Minat 
Membaca Dan Kecerdasan Emosional Siswa. Wahana Didaktika, 15(2), 47. https://doi.org/10.1017/CB09781107415324.004

Handayani, D., \& Agustini, R. (2016). Pengembangan Permainan Tebak Kata sebagai Media Pembelajaran Pada Materi Kimia Unsur. Unesa Joirnal of Chemidal Education, 5(2), 503-510. https://doi.org/10.1017/CB09781107415324.004

Haryadi, T., \& Ulumuddin, D. I. I. (2018). Penanaman Nilai dan Moral pada Anak Sekolah Dasar dengan Pendekatan Storytelling Melalui Media Komunikasi Visual. ANDHARUPA: Jurnal Desain $\begin{array}{lllll}\text { Komunikasi Visual } \quad \text { \& } \quad \text { Multimedia, } & \text { 2(01), }\end{array}$ https://doi.org/10.33633/andharupa.v2i01.1018

OECD. (2015). PISA 2015 Results in Focus. In OECD Publisher. https://doi.org/10.1596/28293

OECD. (2019). PISA 2018 Insights and Interpretations. In OECD Publishing. https://www.oecd.org/pisa/PISA 2018 Insights and Interpretations FINAL PDF.pdf

Patiung, D. (2016). Membaca Sebagai Sumber Pengembangan Intelektual. Al Daulah : Jurnal Hukum Pidana Dan Ketatanegaraan, 5(2), 352-376. https://doi.org/10.24252/ad.v5i2.4854

Sularso, P. (2020). Rendahnya Minat Baca Berpengaruh Terhadap Kualitas Bangsa. https://gpmb.perpusnas.go.id/index.php?module=artikel_kepustakaan\&id=42

Tirtayati, N. P. E., Suarni, N. K., \& Magta, M. (2014). Penerapan Metode Pemberian Tugas untuk Meningkatkan Kreativitas Anak melalui Kegiatan Menggambar Bebas. Jurnal Pendidikan Anak Usia Dini, 2(1).

Widodo, M. C., \& Harini, M. (2016). Pengaruh Kegiatan Menggambar dengan Krayon terhadap Kemampuan Motorik Halus Anak Usia 5-6 Tahun Di Tk. Satu Atap Pekayon 15 Pasar Reho Jakarta Timur. Permata: Jurnal Pendidikan Anak Usia Dini, Edisi Khus, 18-26. 